\title{
Representaciones sociales de migrantes peruanos sobre su proceso de integración en la ciudad de Santiago de Chile
}

\author{
Osvaldo Torres G. \\ Universidad Central, Santiago, Chile. Email: otorresg@ucentral.cl \\ Alejandro Garcés H. \\ Universidad Católica del Norte, San Pedro de Atacama, Chile. \\ Email: ajgarces@gmail.com, agarces@ucn.cl
}

\begin{abstract}
Resumen: El presente artículo busca presentar los resultados de un estudio desarrollado entre los años 2011 y 2012, sobre las representaciones sociales y percepciones de los migrantes peruanos acerca de su proceso de integración en Santiago de Chile, particularmente respecto del acceso a los servicios públicos de educación, salud y vivienda. A partir de una metodología cualitativa, estos servicios son puestos bajo la mirada de los discursos de los migrantes peruanos, develando la discriminación de la que son objeto debido a su procedencia nacional, así como otras formas de exclusión derivadas de su origen popular, y retratando a la ciudad de Santiago como un escenario receptor de flujos migratorios internacionales.

Palabras clave: migración peruana, servicios públicos, representaciones sociales, discriminación.
\end{abstract}

\section{Peruvian migrants social representations regarding their integration process to the city of Santiago, Chile}

Abstract: This article means to present the results of a study developed between 2011 and 2012, referring to the peruvian migrants social representations and perceptions of their integration process in Santiago, particularly those regarding the access to health, education and housing public services. Starting from a qualitative methodology, these services are brought to the attention of the peruvian migrants discourses, exposing the discrimination upon them as a product of national origin, as well as other forms of exclusion associated to their coming from a popular sector, and portraying the city of Santiago as a recipient scenario of international migratory flows. discrimination.

Key words: Peruvian migration, public services, social representations,

\section{As representações sociais dos migrantes peruanos em seu processo de integração na cidade de Santiago de Chile}

Resumo: Este artigo discute os resultados de um estudo realizado entre 
2011 e 2012 sobre as representações sociais e percepções dos imigrantes peruanos sobre o seu processo de integração em Santiago de Chile, especialmente no que diz respeito ao acesso à educação pública , saúde e habitação. A partir de uma metodologia qualitativa, esses serviços são colocados sob o olhar dos discursos dos imigrantes peruanos, revelando a discriminação que são submetidos por causa da sua origem nacional, e outras formas de exclusão resultantes de sua origem popular, e que retrata a cidade de Santiago como um cénario receptor de migração internacional.

Palavras-chave: Migração peruana, serviços públicos, representações sociais, discriminação.

\section{Introducción}

La investigación desarrollada entre mayo de 2011 y septiembre de 2012 tuvo como propósito comprender las formas particulares a través de las cuales la población peruana radicada en la ciudad de Santiago ha ido conformándose una opinión e imagen sobre los servicios públicos asociados a su bienestar social, tanto en el plano de las instituciones como de las situaciones específicas de su experiencia. Los servicios de educación, salud y vivienda son puestos bajo la mirada de los discursos de los migrantes peruanos radicados en la ciudad de Santiago, configurando un panorama complejo de relaciones que van desde la discriminación producto de su procedencia nacional hasta diversas formas de exclusión derivadas de su origen popular, pasando por articulaciones específicas con el sector público según género y edad, y por las funciones propias de estos servicios públicos en cuanto componentes de las políticas sociales de la nación.

Como es obvio, los discursos de los migrantes peruanos se estructuran desde una matriz comparativa respecto de su experiencia de vida previa; sin embargo, no por ello dejan de reconocer las condiciones concretas en las que viven, y ante las cuales desarrollan estrategias particulares que les permiten hacer uso de los servicios sociales sin ver diluida su identidad cultural. Esto, junto con las políticas estatales y leyes sobre migración hoy materias de discusión, influye de manera importante en su búsqueda de una «integración diferenciada» (entendida como aquella que mantiene cierto estilo de vida particular) a la sociedad chilena, utilizando los servicios disponibles, reclamando cuando piensan o sienten que sus derechos han sido vulnerados y asentando social y territorialmente una presencia peruana en la ciudad, sin enmascararse ni aceptar la idea hegemónica de ser «asimilados».

\section{Las representaciones sociales en el estudio de las migraciones}

La adopción por parte de este estudio del enfoque de las representaciones sociales permite considerar aspectos que las macroteorías prece- 
dentes sobre el tema migratorio tienden a ignorar. La construcción del marco teórico de nuestro estudio nos colocó en una perspectiva crítica respecto de los enfoques neoclásicos o economicistas, que reducen la cuestión migratoria a las decisiones maximizadoras del individuo, al cálculo costobeneficio, y en términos culturales, conducentes a la asimilación de los migrantes en las sociedades de destino (Kearnet 1986, Arango 2003).

Por el contrario, desde nuestra perspectiva la gestación de redes y/o espacios transnacionales de circulación adquiere para el migrante un significado especial, no sólo en cuanto referencias a su lugar de origen sino también como mecanismos de traducibilidad cultural que le permiten adecuarse a las nuevas formas que adopta la vida cotidiana y a los nuevos significados que adquieren símbolos, objetos y prácticas que le parecen similares pero que pueden ser distintos en el «otro lugar», el de llegada (Glick Schiller, Basch y Blanc-Szanton, 1992). En este proceso ocurre una especie de negociación social e individual que implica la adaptación y la mantención de las identidades de origen, cuestión que se irá expresando tanto en las formas de representación que adquieren para el migrante su lugar de origen y su cultura que le provee de una forma de estar en el mundo y actuar en él, como las que intenta comprender y asumir en el lugar que lo recibe y que le permitirán desarrollarse. Este proceso complejo no es individual, pues está marcado por la experiencia de otros como él o ella, por los prejuicios existentes y por las expectativas que se poseen respecto de esta fase vital. La investigación social desde la perspectiva de las representaciones sociales implica, respecto de otros enfoques analíticos de las ciencias sociales, una manera bastante peculiar de deslindar el «objeto de estudio». Su mirada se centra en el proceso de construcción de sentido que los sujetos llevan a cabo respecto de su vida en sociedad.

El análisis clásico de las migraciones puede proponerse investigar los flujos demográficos, su impacto en el empleo, en los servicios sociales, las tensiones legales, entre otros temas, para lo cual también sus métodos de investigación y técnicas de producción de información están bien definidas en el plano de la estadística, las encuestas, los grupos de control, etc. La opción por el enfoque de las representaciones sociales implica, en cambio, un enfoque teórico que pone de relieve aspectos cualitativos más complejos. Retomando el concepto durkheimiano, Moscovici (1961) subrayó el carácter mixto, dual, de las representaciones sociales, ubicándolas en el cruce de diversos polos: lo individual y lo social, lo psicológico y lo sociológico, lo sensorial y lo intelectual, el sujeto y el objeto, la representación y la acción. De la misma forma, destacó las múltiples fuentes opiniones, percepciones, imágenes y otros materiales de las que ellas se nutren. En cuanto «saberes prácticos», estos conjuntos de materiales figurativos y simbólicos heterogéneos, propios de las en palabras de Moscovici: «sociedades diferenciadas y móviles», surgen de la acción y se orientan hacia ella especialmente hacia la experiencia cotidiana, tornándose particularmente útiles cuando los individuos o grupos que los elaboran y emplean se hallan enfrentados a situaciones de movilidad o cambio. De acuerdo a Jodelet (1989) «acoger un elemento nuevo» una situación, una temática, una realidad des- 
conocida corresponde a la principal función cognitiva de las representaciones sociales en cuanto forma de conocimiento creativa y no sólo representativa, uno de cuyos mecanismos de elaboración fundamental es el recurso a «saberes anteriores reactivados». De acuerdo a esta investigadora, las representaciones sociales constituyen también «una guía para la acción y los intercambios cotidianos», y que en ciertos contextos, «puede entrar en conflicto con la visión de otros grupos». Esta dinámica propia de las representaciones sociales indica que ellas también poseen, en cuanto conocimiento socialmente elaborado, un componente identitario. A través de ellas los individuos acceden a una forma compartida de ver y actuar en el mundo. Investigar las representaciones sociales de un colectivo humano determinado lo que Jodelet denomina sus «condiciones de producción y circulación», sus "procesos y estados» y su «estatus epistemológico», en este caso, de los migrantes peruanos, implica prestar atención a sus discursos, pues en ellos está entretejido el sentido que otorgan a sus experiencias y los modos en que estas experiencias se les presentan y representan.

Este enfoque nos lleva a considerar varios niveles posiblemente problemáticos para la integración sociocultural de los migrantes y para la comprensión de la sociedad chilena en el plano de sus conductas, discursos y valoraciones de lo local. Entre los elementos a considerar están: a) la lengua común que facilita la conversación, pero a la vez apela a los nacionalismos al presentar códigos particulares herederos de una historia cultural diferenciada y tensionada entre ambos Estados; b) el dispar grado de valoración de la sociedad indígena prehispánica en la construcción de la nación, que puede ser un factor diferenciador que aliente la discriminación hacia la población peruana migrante; c) los sentidos que se le otorgan a determinados símbolos que pueden ser comunes, pero que poseen significaciones distintas, como la religiosidad popular, el estatus social asociado a determinados objetos, el resguardo de ciertos modos de vida y sociabilidad, etc. Por otro lado, las instituciones públicas, en cuanto proveedoras de servicios básicos, vitales para la integración de los migrantes, se convierten para ellos en una superficie de contacto cuasi-obligada. Por un lado ellas proveen vías de integración a la nueva realidad que enfrentan los migrantes; por otro, ellas mismas constituyen espacios complejos a los que ellos deben «entrar», desplegando representaciones y estrategias de aproximación. Las representaciones sociales construidas en torno a los servicios públicos por los migrantes peruanos en Santiago requieren de un tratamiento analítico particular que permita, por un lado, conocer los planos conflictivos y potenciadores de su proceso de integración, y por otro, establecer sus expectativas respecto del concepto de integración, toda vez que ella puede entenderse como transitoria o permanente, según el proyecto individual o colectivo previo a la decisión de emigrar, o si este proyecto ha sufrido cambios.

Analizar el sentido que tienen para la o las culturas de los migrantes peruanos determinadas conductas, objetos o palabras implica comprender los sistemas de representación social con los que ellos operan, esto es: sus sistemas de clasificación, las formas como relacionan determinados con- 
ceptos y cosas, y el lugar que les asignan dentro de su comprensión del mundo. En este sentido, las representaciones sociales son un mapa mental que les permite decodificar los mensajes dirigidos a ellos, ya sea a través de la información que reciben, la conducta de la que son objeto el trato y lo que se dice sobre ellos. Siguiendo a Hall (1997) y retomando los planteamientos de Moscovici y Jodelet afirmamos que el sentido no está en las cosas, sino que es producido por determinadas prácticas colectivas que hacen que las cosas sean significativas. No hay construcción de sentido sin una referencia a otros, a prácticas vividas que encuentran su fundamento en lo social. Según Ibáñez, las representaciones sociales «son producciones mentales que trascienden a los individuos particulares y que forman parte del bagaje cultural de una sociedad. Es en ellas como se forman las representaciones individuales que no son sino su expresión particularizada y adaptada a las características de cada individuo concreto» (Ibáñez, T., 1988: 19). Esto hace posible un universo de conceptos compartidos, pero que al ser procesado de forma individual permite no sólo la reproducción de los sentidos otorgados a las cosas mecanismo de producción clave de las representaciones sociales, sino también su transformación de acuerdo a las prácticas socioculturales de los grupos e individuos. En suma, las representaciones sociales son pensamiento constituido, en cuanto son fijadas transitoriamente por un grupo humano con el fin de normalizar la vida en sociedad y los eventos asociados a ella, pero a la vez son pensamiento constituyente, en tanto construyen la realidad de acuerdo a sus códigos.

\section{Metodología}

El enfoque metodológico de nuestra investigación fue de tipo cualitativo, entendido como «conjunto de prácticas interpretativas que hacen al mundo visible, lo transforman y convierten en una serie de representaciones en forma de observaciones, anotaciones, grabaciones y documentos. Es naturalista (porque estudia los objetos y seres vivos en sus contextos o ambientes naturales) e interpretativo (pues intenta encontrar sentido a los fenómenos en términos de significados que las personas les otorguen)» (Hernández, Fernández-Collado y Baptista, 2006: 9). Los métodos cualitativos son más apropiados cuando el objeto de la investigación es la experiencia subjetiva y el significado que cada persona le confiere. En este sentido se puede entender que sea apropiado aplicarlos también al estudio de procesos, teniendo en cuenta la particular atención que prestan a los factores ambientales, tales como el contexto o la situación social de los actores involucrados (Devine en Marsh y Stoker eds., 1997: 146). Este tipo de método pretende captar y reconstruir significados, más que describir hechos sociales. Así también, al utilizar el lenguaje como objeto de estudio, indaga en los conceptos y metáforas de los actores, prescindiendo de números y pruebas estandarizadas, de encuestas y experimentos, que no lo conducirían a lo que busca. Utiliza procedimientos organizados y sistemáticos, pero al mismo tiempo es flexible e inductivo, lo que lo libera de la pretensión de generalizar sus resultados y lo lleva a concentrarse y valorizar lo particular: «la tarea que se fijan a sí mismos estos métodos es la de 
captar el significado completo de los universales concretos que se dan en cada fenómeno social» (Ruiz J., 2003, 23-25). Como el problema planteado en nuestra investigación dice relación con las representaciones sociales que construyen los peruanos residentes en Santiago de Chile respecto de su proceso de integración en la sociedad de acogida, dentro del cual juegan un rol preponderante los dispositivos estatales dirigidos hacia ellos, en particular los servicios públicos de educación, salud y vivienda, debe considerarse que, para efectos del análisis que sigue, se trata de expresiones y construcciones sociales que no pretenden ser representativas del universo o total de la población estudiada (Hernández, Fernández-Collado y Baptista, 2006: 562).

De acuerdo a lo anterior, la muestra utilizada en la presente investigación puede definirse como no probabilística. Más bien, se trata de una muestra estructural, pues las unidades seleccionadas poseen perfiles diferenciados dentro del campo que ellas mismas definen. Se buscó sobre todo resaltar situaciones, procesos o episodios significativos para un grupo social definido migrantes peruanos radicados en la región Metropolitana, con el fin de capturar la diversidad de posiciones socio-discursivas presentes en él, más que su representatividad respecto del universo. Ello se complementó con una muestra de expertos o actores relevantes, definidos como funcionarios públicos de las agencias estatales de los sectores de educación, vivienda, salud y del nivel municipal, sumando un total de nueve entrevistas. Las unidades de análisis utilizadas fueron significados, prácticas, episodios, así como encuentros, papeles, relaciones, grupos y organizaciones de los sujetos estudiados, englobando también aspectos ligados al estilo de vida de los mismos.

La otra herramienta utilizada fueron los grupos de discusión (GD). Grupos de sujetos pertenecientes a la muestra se reunieron en torno a una mesa o en una sala apta para la conversación, junto con el investigador, quien propuso un tema general de conversación y actuó como moderador. El atractivo de este instrumento residía en la posibilidad de generar un «coloquio», una discusión, que, aunque dirigida por el investigador, pudiera dar lugar a una dinámica espontánea a lo largo de la cual aflorasen intereses, preocupaciones o necesidades latentes del grupo estudiado (Anduiza, Crespo y Méndez, 1999: 87). Se efectuaron tres grupos de discusión, abarcando un total de 25 personas de distintas comunas, sexo y edad.

\section{Resultados}

El acceso a los servicios públicos de educación, salud y vivienda por parte de los migrantes peruanos, así como las representaciones sociales construidas por éstos respecto de aquéllos, puede entenderse dentro de una lógica de satisfacción de determinadas necesidades y derechos sociales y económicos enmarcados dentro de una estructura institucional, situando a los migrantes como meros «usuarios» o receptores de un conjunto de servicios. Sin embargo, en la práctica, tanto el acceso a estas agencias como las 
representaciones que los migrantes construyen sobre ellas se encuentran atrapados en la trama de opiniones y percepciones mutuas entre nativos e inmigrantes, de imaginarios sociales construidos en torno al fenómeno de la migración, su magnitud, grado de integración, aporte a la sociedad receptora y la supuesta disputa por un «bien escaso». En este sentido, la tensión entre los aspectos simbólicos y materiales que observamos y que influyen en nuestro análisis actúa como una advertencia sobre el peligro de «esencializar» la diferencia cultural que introduce la migración internacional, inhibiendo cualquier inclinación a explicar los diferenciales de acceso a los servicios públicos como una cuestión de capacidades o disposiciones adscritas a priori al colectivo peruano.

Si bien la magnitud de la migración peruana en Chile, y en general la migración internacional, no alcanza niveles que pongan en jaque las capacidades de los servicios públicos del Estado chileno, la sombra de la competencia por recursos escasos (y no nos referimos exclusivamente al empleo, sino también a los servicios públicos que estudiamos) se cierne sobre las relaciones entre migrantes y autóctonos, condicionando, por ejemplo, la actuación de los funcionarios públicos que atienden o proveen de los servicios públicos en cuestión (Martinez Pizarro 2003a y 2003b, Stefoni 2002, Araujo, Legua, et. al. 2000). Como se ha señalado, «la competencia por los recursos está muy relacionada con la sobredimensionalización del volumen de inmigrantes, con la ubicación de autóctonos en inmigrantes en la estructura ocupacional y con la percepción, muchas veces deformada, que la sociedad receptora tiene sobre cuáles son las condiciones de vida de los inmigrantes» (Solé, Parella et.al., 2000: 151). Lo preocupante a este respecto es que, de producirse esta competencia, ella tendrá lugar probablemente en los territorios de los sectores más bajos o socialmente vulnerables, cooperando a una mayor emergencia de actitudes xenófobas o racistas que ya se observan en la ciudad Santiago.

A continuación presentamos una síntesis de los principales resultados obtenidos en cada uno de los ámbitos de servicios públicos analizados, para luego aportar unas conclusiones generales que nos permitan obtener una visión de conjunto de estas representaciones en relación con la integración de la población migrante en Chile.

\section{A) Educación}

Los discursos sobre el ámbito de los servicios de educación pueden ordenarse considerando dos dimensiones. En primer lugar, la dimensión de convivencia escolar, situada en el eje entre los derechos de los estudiantes y el ejercicio del bullying. Y en segundo lugar, la dimensión de inclusión social, que se configura en el eje entre la integración y la discriminación en el sistema educativo. La convivencia escolar se refiere al conjunto de experiencias que ocurren en el interior de la escuela, en particular a la capacidad que tiene la institución escolar de respetar los derechos de los agentes de la educación y de proveer un clima que evite las prácticas de discriminación y que pueden llegar a la agresión entre estudiantes, concretamente hacia aque- 
llos que ostentan la condición de estudiantes extranjeros. La inclusión social, por otro lado, hace referencia a cómo las prácticas institucionales impulsadas por la dirección de la escuela, junto con las leyes y reglamentos, posibilitan la integración cultural que en ocasiones podría entenderse como la búsqueda de la asimilación o consolidan una situación de discriminación.

Cuadro 1. Representaciones sociales sobre el sistema educativo.

\begin{tabular}{|l|l|}
\hline \multicolumn{2}{|c|}{ REPRESENTACIONES SOCIALES: EDUCACIÓN } \\
\hline \multicolumn{1}{|c|}{ Dimensiones } & \multicolumn{1}{c|}{ Ejes } \\
\hline Convivencia escolar & Derechos - Bullying \\
\hline Inclusión social & Integración - Discriminación \\
\hline
\end{tabular}

Un primer elemento relevante es que no se percibe una diferencia importante entre los sistemas educativos de ambos países. No se menciona una incapacidad de aceptación o un rechazo activo por parte de la burocracia del Estado de Chile, tampoco por una dificultad o incapacidad para adaptarse a los requerimientos de la educación chilena por parte de los estudiantes peruanos o de sus familiares. La educación también significa para ellos como para los chilenos no sólo un espacio de «disciplinamiento» o «instrucción» para sus hijos, también es concebida como una posibilidad de movilidad social futura.

Dicho lo anterior, los principales aspectos diferenciadores radican en la valoración que tienen los migrantes del rol social de los profesores, y en particular al interior de la jerarquía de la escuela. Denotan una devaluación del estatus profesoral en relación con el «respeto» que se merecen por parte de los estudiantes y también por su falta de vocación. En este juicio puede jugar un papel importante la concepción que los apoderados peruanos tienen sobre la escuela en cuanto lugar al que «se va a aprender», y por tanto, en donde los estudiantes deben obedecer. Ello entra en conflicto con la realidad de la educación chilena y su cobertura segmentada, que hace hace que a la educación municipal ingresen estudiantes de sectores empobrecidos, cuyos padres chilenos tienen escasa escolaridad y poca valoración de la escuela como vehículo de movilidad social (en tanto, para ellos, efectivamente ella no ha cumplido este papel).

Otro elemento destacado por los migrantes son los tipos de colegios. Más allá de su carácter público o privado, los apoderados peruanos ponen atención a las características específicas impuestas por las direcciones o la comunidad escolar, lo que se expresa en los múltiples cambios de colegio que efectúan hasta encontrar uno que se alinee con sus expectativas. Esta movilidad resulta interesante, pues de alguna forma ha obligado a 
modificar la «oferta pública» comunal de integración de las comunidades extranjeras, y la peruana en particular, toda vez que el sistema de subvención presiona a la educación municipal para que retenga matrícula (estudiantes).

Las prácticas de bullying se presentan de manera transversal en distintos establecimientos. Se trata de abusos de poder de personas o grupos en contra de un «otro extraño» y débil, ya sea por su condición física, su aislamiento de los grupos de referencia, etc. En este sentido, el bullying contra estudiantes peruanos no debiera ser considerado como uno más entre otras formas de violencia psicológica y física, sino más bien como una forma de discriminación racial. Este punto es clave si se quiere resolver el problema al interior de la escuela y no con la salida del «otro extraño» por decisión de los afectados; para ello se requiere ampliar las experiencias positivas de integración respetando la diferencia y adaptando sus contenidos.

La escuela es percibida como un lugar donde se viven o se han vivido experiencias de discriminación, ya sea por formas de trato despectivo o por bullying. En algunos casos ha una reacción de la dirección y en otros se toma la decisión de cambiar el lugar de estudio. Es decir, la escuela aparece como una posibilidad de ser discriminado, y por ello existe la incertidumbre respecto de cómo será este espacio de convivencia. A alguien le puede «tocar», tener «la suerte» de que los compañeros de colegio y la institución sean acogedores con el o la migrante, pero es sólo una de las posibilidades. En ciertos casos los apoderados visualizan la relación profesor-alumno como una experiencia de discriminación, en que sus hijos son tratados de forma especialmente injusta, con conciencia de que se debe a su condición de peruano: «(La profesora) le dice a mi hijo que es un demente, no le hagan caso, él está demente; y le agregó un garabato».

En todo caso, los apoderados de los estudiantes peruanos parecieran tener un papel activo en la defensa de sus hijos e hijas en las reuniones con las autoridades de los colegios o de padres, madres y apoderados, lo que se expresa en variadas menciones a reuniones de este tipo, con resultados diversos. En algunos casos la queja es directamente ante y contra una autoridad del establecimiento educativo: «a sus hijos también le pegan y el director no hace nada; los insultan, de garabatos y uno tiene problemas, va a conversar, le habla (al Director), pero no te conversa muy bien tampoco». A la vez relatan experiencias en que estos derechos son restablecidos y los agresores sancionados: «la profesora fue separada, pensé que me iban a tener con la sangre en el ojo por las buenas notas le dieron beca todo el añocontenta porque hice valer los derechos de mi hijo».

La relación entre los apoderados peruanos y los colegios pareciera ser más activa que en el caso de sus pares chilenos, en tanto hay una preocupación efectiva por evitar que sus hijos sean discriminados. La escuela pública sigue representándose como un lugar importante para el aprendizaje del niño o niña y su desarrollo futuro, pero el hogar es visto como determinante para la formación en los valores propios. 
En la convivencia con otros estudiantes también se presentan experiencias de discriminación que corresponden a una lectura específica sobre el trato que les dan sus compañeros: «Te tratan muy malno te dicen por tu nombre te dicen: oye peruana como una animal si estuvieran llamando». O de forma más directa hay agresión: «(la experiencia en el colegio) el primer año fue complicado, en especial el primer semestre, me hacían bullying, sí igual fue un poco duro. Pero ya no». Esta situación es vista por los apoderados como un componente básico de la formación que se entrega en las familias, más que en la escuela. Es decir, lo que ocurre en esta última es un reflejo de cómo los hijos son formados en sus hogares, lo que permite leer los conflictos entre los estudiantes, no como producto de una institucionalización de la discriminación en el sistema escolar, sino como un correlato de lo que ocurre en las familias: «Pero bullying de 8 añitos eso empieza en la casa, porque ese niño escucha al papá o a la mamáhay un cierto nivel de educación en esas casas».

En otro plano también opera el tema de la calidad de la relación entre el profesor y los estudiantes, pero en un sentido más general. Cuando se piensa que no tienen interés en su actividad, que no se empeñan en enseñar, hay una igualación entre los estudiantes respecto de la calificación de los profesores como malos; en este caso la negación de una educación de calidad opera para todos: "Los profesores, uno que otro son como responsables, les interesa enseñar, otros llegan y dicen ya chao, paso lista, me siento». Esta idea que algunos profesores no se comprometen con la educación de sus hijos, ayuda a reforzar la representación de una escuela pública local que no abre espacio a la superación social y que comparativamente resulta deficitaria respecto de la peruana.

En los discursos de los migrantes se expresa un reconocimiento de una contraposición entre su idea de integración, por un lado, y la discriminación que sufren sus hijos en el sistema educativo, por otro. A la vez, exhiben una clara conciencia de que poseen derechos que deben hacer valer ante el bullying o la discriminación de la que son objeto sus hijos y otros estudiantes.

Esta situación no les impide reconocer las características culturales diferenciadas que existen entre el sistema educativo chileno y el de su país de origen, tanto en la calidad como en la orientación que tienen, y las diferencias culturales respecto del lugar que ocupa la educación y la figura del profesor en el sistema global.

\section{B) Salud}

Las condiciones de la atención de salud brindada a los migrantes en el país tienen un signo contradictorio. Las experiencias son bastante diversas, según sea el tipo de requerimiento de atención realizado y el personal que lo ha recibido. Las principales dificultades se presentan al momento de definir la gravedad o urgencia de una dolencia, y por tanto dicen relación con los tiempos de espera en los centros de atención primaria o de urgencia. 
Una primera cuestión a notar es que la experiencia de la atención de salud está básicamente relatada desde las mujeres, ya sea porque han dado a luz en los hospitales de Santiago, o porque son ellas quienes llevan a los hijos a los consultorios o acompañan a sus familiares a los centros de salud. Los hombres se encuentran en sus lugares de trabajo.

Las representaciones sobre el sistema de salud se organizan de acuerdo a dos dimensiones. La dimensión del acceso incluye tanto experiencias directas de atención como aquellas narradas por conocidos, y se despliega en un eje que va desde las dificultades o facilidades otorgadas a los migrantes, hasta las estrategias que ellos desarrollan ante las situaciones de rechazo, tanto por no haber obtenido atención o por sentirse discriminados cuando ello ha ocurrido. En una segunda dimensión, de calidad de la atención, encontramos la noción de respeto, entendido como lo que una persona debe recibir y dar en este tipo de situaciones, en contraposición a la experiencia de la discriminación, que se relaciona con el maltrato de palabra, las demoras y los intentos de engaño o abuso.

\section{Cuadro 2. Representaciones sociales sobre el sistema de salud.}

\begin{tabular}{|c|c|}
\hline \multicolumn{2}{|c|}{ REPRESENTACIONES SOCIALES: SALUD } \\
\hline Dimensiones & Ejes \\
\hline Acceso & Dificultades y facilidades - Estrategias \\
\hline Calidad & Respeto - Discriminación \\
\hline
\end{tabular}

Como puede observarse, la dimensión de acceso a la salud puede dividirse en dos planos: el de las experiencias individuales que pueden o no ser positivas y que no tienen un carácter generalizable, y el de lo que se asume como un tema estructural que afecta a los migrantes en cuanto usuarios y en su condición de extranjeros. La idea de que el sistema de salud impide el acceso a los migrantes por su condición de tales está ausente en los discursos; más bien se trata de trabas legales impuestas por el país para que ellos se «regularicen» como ciudadanos y accedan como los demás a la atención en el sistema de salud.

Varios discursos asumen que las malas experiencias se deben a la deficiente calidad del sistema, como en el caso de las largas esperas en los consultorios: «Sacar hora hay que ir a las 5 de la mañanauna vez llegué a las 7 y ella llegó como a las 8,40 y no me dieron hora y yo le dije caballero vengo de tan lejos y me dijo no puedono entienden». También existe claridad respecto a que la disparidad en el acceso depende de si se acude al sistema privado o al público; al primero, las mujeres llegan si ellas o sus maridos tienen regularizada su situación laboral y los empleadores cumplen con el pago de cotizaciones. En este caso el sistema opera bien 
porque se paga para ello: «tuve pre y postnatal y como mi esposo trabaja también tuve la posibilidad de ir a una clínica porque escuché de varias personas compatriotas mías que en el Hospital San Borja no las habían atendido bien durante el parto».

Otro requisito para el acceso es la documentación en regla y la inscripción en los consultorios. Hay una estrecha relación entre «tener RUT» o no y por tanto, estar en una situación irregular y las posibilidades de acceso a la atención de salud. Existe también un conocimiento concreto sobre los niveles del Fondo Nacional de Salud, FONASA, y las características de cada uno de ellos, así como diferentes opiniones sobre la equidad en la atención según el nivel o letra que se posea ${ }^{1}$. Sin embargo, las madres evalúan positivamente a la atención primaria, particularmente respecto de los programas de control del niño sano, que surten el efecto de moderar la crítica sobre los problemas en la atención de adultos y el acceso en caso de urgencias: «No me quejo, ni tan buena ni tan mala. Para los chiquillos me han atendido, le han puesto sus vacunas, la leche pero, para los grandes, uff, hay que esperar año a año para que te atiendan».

Muchos de los problemas y dificultades con los que se encuentran los migrantes están también relacionados con la idea de que existe una mala administración de los centros de salud. Es decir, las fallas están en una gestión que no permite que se hagan las cosas de forma más eficiente, que los trabajadores de la salud no pierdan el tiempo y se dediquen a sus funciones específicas. En este caso se reconoce que la calidad de la atención varía de comuna en comuna: «(Los consultorios) están súper mal administrados, las señoritas están ahí y conversan y conversan y las personas afueraestán esperando».

Desde una óptica más general, cabe señalar la posibilidad de que exista una apreciación distinta entre los migrantes peruanos, por un lado, y los funcionarios y médicos chilenos, por otro, respecto de qué es una dolencia grave, e incluso respecto del concepto mismo de enfermedad. La crítica sobre la mala atención no debe ser tomada solamente como un problema endémico del sistema público de salud, sino también desde la perspectiva de las fuentes culturales de las representaciones sociales socialización, endoculturación, formas de crianza, etc., que pueden chocar con otras construcciones sociales sobre la salud o la enfermedad. En este caso, la concepción de las madres peruanas sobre la salud y el cuidado de los hijos pueden estar en colisión con las posibilidades del sistema de salud de responder a estas necesidades básicas, pero también social y culturalmente construidas. Los discursos establecen un contrapunto respecto del sistema de atención primaria del Perú, en donde «los médicos van a buscarte».

Las migrantes usuarias del sistema de salud también entienden que deben desarrollar sus propias estrategias de acceso a la atención cuando ésta se ve obstruida o se complica. Por una parte se asume que no todo el personal recibe a los migrantes del mismo modo ni tiene una similar disposición a atenderlos. Existen modos de aproximación que dan buenos resul- 
tados: "Yo tuve que hablar con la asistenta e igual me ayudó harto porque me conseguía horas de médico y me tocó una muy buena doctora en el consultorio Bustos». También otros dirigidos a salvar los escollos legales: « un amigo chileno me prestó su RUT para ir al SAPU de Independencia». Las experiencias dispares refuerzan la idea de la incertidumbre: a una persona le puede «tocar» una buena doctora, es una cuestión de suerte: «En mi caso no me gustó tanto como algunas que han tenido más suerte a mi no porque me hicieron mucho sufrir».

En cuanto a la discriminación, existe la idea de que las relaciones comunicativas entre las personas deben establecerse desde la igualdad y considerando las diferencias entre ambas naciones. Los peruanos no desconocen las formas de trato informales que los chilenos usan entre desconocidos, ni ignoran que en una situación de atención de público se encuentran en desventaja en cuanto usuarios. Su reclamo tiene que ver con la ausencia de una relación de respeto. Observan que si a los chilenos se les replica o replicara de la misma manera que a ellos «tirando la talla» «entonces no les gusta». La relación funcionario-usuario también se vive como más agresiva; el personal trata de "pasar a llevar», sin considerar la situación de los demás: "Aparte que el servicio es malo, cuando ven a una persona que pueden pasar sobre ella, lo hacen».

Los juicios de los migrantes respecto del trato que brindan los funcionarios de la salud son claros en términos de relativizar las experiencias y no generalizar: «es el funcionario que le falta tino y capacidad de poder dialogar con otra persona y ponerse en los pantalones de esa otra persona». Pero no todos los funcionarios de todos los centros de salud los tratan igual: «me he atendido en varios consultorios y Recoleta es la peor, pero no he sentido discriminación es que ahí está centrado mayormente los migrantes y aunque no lo crea, los funcionarios mismos que atienden ahí se han puesto como racismo».

La idea de respeto resulta clave para la valoración de las formas de discriminación que han vivido. Por ejemplo, la experiencia de las mujeres que han sido madres puede resultar traumática: «a mi me han dicho que así las tratan (que peruana abre las piernas!), cuando van a labores de parto que suelen gritar". "Aparte que el servicio es malo, cuando ven a una persona que pueden pasar sobre ella, lo hacen». En otras palabras, esta queja puede entenderse en tres niveles: una mala atención en cuanto sienten que se les ha faltado el respeto, porque son «pasados a llevar» es decir, no son considerados como personas con opinión, y por último, porque en cuanto migrantes no deberían quejarse de la atención que se les «da».

Hay experiencias particulares que les permiten relativizar la vivencia de la discriminación. Por un lado, pueden comparar lugares en donde han sido discriminados con otros en que no lo han sido. Esto les permite moderar la sensación de encontrarse en un país hostil. Cuando la comparación se hace con lo que ocurre en otros países, la situación actual resulta 
aun más relativizada: «Con el respeto que cada uno se merece, eso depende de cómo viene de su casa y padresyo también soy peruanay no es que tu eres peruano, yo soy chilenoa nivel mundial, siempre pasa».

Un último elemento importante es la capacidad de hacer valer los derechos ante situaciones de vulneración. Resulta claro que hay hechos de discriminación que son procesados por los migrantes peruanos como producidos por personas, mientras otros son provocados por instituciones. Los primeros giran en torno a la casuística de las distintas comunas, tipos de atención de salud requerida y personas involucradas (médicos, enfermeras o personal de apoyo), en tanto que los segundos dependen de factores como el tipo de documentación que se posea y el tiempo que se ha permanecido en el país, el que determina el grado de conocimiento sobre las estrategias que se pueden utilizar en el sistema de salud para evitar ser rechazado. Aparejada a lo anterior hay una conciencia del deber de no dejarse atropellar y saber defender su derecho al acceso que les corresponde como usuarios del consultorio o por ser cotizantes de FONASA. En general, el objetivo de los migrantes es regularizar sus papeles y estadía para así acceder al seguro de salud que les posibilite reclamar sus derechos y responder a quienes les faltan el respeto, como haría cualquier usuario.

\section{C) Vivienda}

Los colectivos de migrantes de origen popular se ubican usualmente en zonas urbanas antiguas y muchas veces habitacionalmente degradadas, donde el costo de residencia es más barato; se trata de emplazamientos vulnerables. Esto se asocia, por un lado, a su situación civil a la dificultad para acceder a regularizar sus documentos y permisos de trabajo y a la precarización de su mano de obra dentro del mercado laboral de la sociedad anfitriona, y por otro, a la superposición de diversas formas de discriminación por nacionalidad, etnia, carácter extranjero, clase social, edad y género en el caso de las mujeres, que los inmigrantes suelen enfrentar en el marco de su proceso de integración a una nueva sociedad.

En una primera dimensión, la del mercado de la vivienda, nos encontramos con un mercado de alquileres totalmente desregulado, ubicado, de acuerdo al Censo 2002 y a otras fuentes, en las comunas de Santiago Centro, Recoleta, Independencia y Estación Central, entre otras. La especulación con el precio de los arriendos sin contrato de por medio, ya se trate de casas o habitaciones, y con varias familias compartiendo un baño o cocina marca las condiciones de vida en estos vecindarios, y junto con ello la percepción de discriminación tanto por el hecho de ser extranjero como por residir en un barrio concreto, sin posibilidades de ejercer el derecho a una vivienda digna. Desde este punto de partida, la reacción de los migrantes peruanos tiende paulatinamente al surgimiento de organizaciones, con la particularidad de que se trata de organizaciones que incorporan a migrantes de otras nacionalidades, e incluso a chilenos. Esta primera dimensión del mercado de la vivienda condiciona el tipo de representaciones construidas por los migrantes peruanos respecto de su acogida en la sociedad chilena, 
pobladas de situaciones de abuso y discriminación por parte de arrendatarios y otras figuras de poder que deciden dónde se puede vivir y dónde no. En el polo opuesto a este tipo de relaciones se ubica la posibilidad de desarrollar lazos de solidaridad entre pares, utilizar la ley de subsidio habitacional y reclamar la igualdad de derechos con el objetivo de obtener el apoyo estatal para comprar una vivienda.

Cuadro 3. Representaciones sociales sobre los servicios de vivienda.

\begin{tabular}{|c|c|}
\hline \multicolumn{2}{|c|}{ REPRESENTACIONES SOCIALES: VIVIENDA } \\
\hline Dimensiones & Ejes \\
\hline Mercado inmobiliario & Discriminación - Estrategias de asociatividad \\
\hline Vivienda & Amenaza de desprotección - Redes de apoyo \\
\hline
\end{tabular}

La segunda dimensión se organiza a lo largo del eje que va entre la amenaza de desprotección y desamparo, por un lado, y el uso de redes sociales de apoyo, por otro. Estas redes de apoyo se basan en lazos de parentesco de distinto grado, así como en nexos entre coterráneos individuos oriundos del mismo pueblo o ciudad del Perú que permiten depositar confianzas en personas que no son un «otro» tan diferenciado. La red que se establece desde el lugar de residencia es una de las más fuertes, al punto de abarcar barrios completos («Lima Chica», etc.), con ferias de productos típicos, cocinerías, restaurantes populares, centros culturales y asociaciones (Garcés 2011, Luque 2007).

Diversas comunas, como Independencia, Recoleta, Santiago Centro y Estación Central, acogen una alta cantidad de población peruana, generándose durante la última década importantes asentamientos en algunos barrios. El impacto de estas transformaciones en estas zonas urbanas puede observarse en diversos planos: reactivación del comercio, tanto del ya existente como del regentado por miembros de la comunidad migrante; modificación de las costumbres y estilo de vida de la población originaria; vinculación y mezcla de poblaciones de diversas nacionalidades, incluida la chilena; y finalmente, el ya mencionado negocio del arriendo.

Como es de esperar, hay una marcada relación entre las experiencias de abuso vinculadas con la especulación inmobiliaria y la sensación de discriminación. Dentro de esta suerte de subsector del mercado de la vivienda en Santiago, los migrantes peruanos ocupan una posición de desventaja, lo que les hace vulnerables al abuso por parte de los propietarios: «porque cada persona tenemos sobre todo ese derecho de poder vivir en un hogar digno y a la misma vez ver nuestros hijos no vivir bajo de un techo muy limitado, sufrimos y sobre todo nuestros hijos que están estudiando». 
A la vez, la incipiente asociatividad expresada en diversos comités para la vivienda habla de una conciencia respecto de la existencia de mecanismos de postulación que pueden lograr el objetivo tal vez inesperado respecto de la migración de poseer una casa propia. Esta tentativa se ve impulsada por unas condiciones de sobrevida hacinamiento, mala higiene muchas veces deplorables, las que se ven agravadas por los requerimientos de envío de dinero al país de origen, donde permanecen los hijos o familiares a quienes en ocasiones se desea atraer para consolidar la estadía en Chile.

En la comuna de Santiago la percepción sobre la ocupación de las zonas céntricas de la ciudad está presente también en el diagnóstico realizado desde los servicios municipales, para quienes esta dinámica no aparece en ningún caso como sorpresiva, sino más bien como recurrente en ciudades receptoras de población migrante: «Tú te encuentras con una dinámica urbana que es la dinámica de casi de todos los casos históricos de todas las ciudades del mundo, en que en el casco histórico antiguo, se tiende a instalar familias pobres y principalmente inmigrantes, es un fenómeno urbano que en mi opinión tiene que ver con que las personas que están en otro país, tienen que buscar un mecanismo de sobrevivencia donde aparte de trabajar en la parte de la economía más básica y peor remunerada, tienen que generar ahorros suficientes para mandar platas de vuelta y eso, lo obliga a ellos a vivir en muy malas condiciones donde en el casco urbano antiguo esto queda oculto y no es explicito como la mediagua con una bandera en la periferia».

Este municipio sostiene el carácter universal de los servicios que presta, sin distinción por origen nacional, pero con el requisito de que los usuarios cuenten con la respectiva cédula de identidad otorgada por el Ministerio del Interior y tengan sus permisos de residencia al día. En particular, esta municipalidad cuenta con un servicio radicado en el Área Social especializado en la atención de las necesidades de la población migrante, no sólo peruana, incluido el acceso a la vivienda. La residencia en estas viviendas en condiciones de hacinamiento puede mantenerse por períodos muy prolongados.

En esta línea, lo narrado por un funcionario municipal de la comuna de Santiago respecto de los abusos cometidos contra migrantes resulta sintomático: «Nosotros acá antes del terremoto, finales del 2009 encontramos un galpón industrial en Mapocho, un señor había arrendando y este arrendador construyó mediaguas bien hechas, con buena instalación eléctrica y arrendaba a un precio muy caro con una única entrada, un portón metálico y tenía a un matón en la entrada que controlaba la entrada, adentro había un pequeño patio cubierto, interesante porque los niños no salían a la calle pero muy malas condiciones higiénicas, tenían un solo baño hombres, un baño mujeres, alrededor de 30 de estas casas, y cuando nosotros nos enteramos, tomamos contacto con el dueño; el dueño no sabía que su propiedad estaba siendo utilizada para eso. Y nosotros fundamentalmente nos hemos ido enterando a partir de los conflictos; acá, de repente, hay un incendio, o la Dirección 
de Obras declara ilegal la ocupación de una vivienda y tienen que salir y la fuerza pública los saca y al otro día el mismo municipio tiene que estar poniendo colchonetas, camiones y ayudándolos socialmente».

Los abusos y las condiciones hacinamiento en que se ven forzados a vivir los migrantes quedan así expuestos en toda su magnitud, haciéndose hincapié en los riesgos sanitarios e incluso de accidentabilidad: «lo más complicado es que esta gente tiene un solo baño para tres o cuatro familias, niños, adultos, entonces es el montón de incendios que se han dado en Santiago y esos son peruanos». La estructura de la oferta habitacional para los migrantes radicados en Santiago no se restringe a lo que ocurre en este municipio central, sino que se extiende hacia otros territorios en donde también puede verificarse su presencia, como en el caso de la comuna de Independencia.

En el ámbito de la acción municipal, específicamente en cuanto al alquiler de viviendas, se reconoce la total ausencia del Estado en cuanto garante de los derechos de las personas, cuestión que a su vez tiene una consecuencia directa no sólo en el acceso a la vivienda, sino también en la calidad y condiciones de seguridad de la misma: «Aquí existieron antes, incluso en el 1800, normativas de arriendo y efectivamente el arriendo tiene que tener ciertos niveles de calidad y cierto nivel de corresponsabilidad entre arrendador y arrendatario, pero fundamentalmente tiene que haber un arriendo responsable. [] No (hay tutela del Estado) porque nuestra Constitución lo dejó fuera, y eso hoy día es un fenómeno institucional interesante se necesita una mayor intervención del Estado, más eficiente, con menos funcionarios, más transparente, pero se necesita más presencia del Estado, este no es el Chile de mediados de los 80, en mediados de la dictadura donde había que liberalizarlo todo, disminuir el Estado, achicar el Estado, porque los problemas son más complejos entonces hoy día problemas de hacinamiento en una casa es un problema muy complejo socialmente y es un problema muy complejo desde el punto de vista de salud, es un problema muy complejo de la sociedad, desde el punto de vista del barrio» (Funcionario municipal - comuna de Santiago).

En cuanto a la vivienda nueva, nuestra exploración indica que los municipios terminan asumiendo un rol mediador entre la población migrante y el SERVIU (Servicio de Vivienda y Urbanismo), órgano público encargado del desarrollo urbanístico y de vivienda. La sensibilidad del municipio apunta aquí a tratar de solventar la falta de información con la que deben lidiar los usuarios migrantes de este servicio: «Sale la demanda que esté bien informada y hay postulaciones en tal fecha, nosotros hacemos las postulaciones, es que en el SERVIU la orientación no es muy buena, es que el SERVIU perdió la sensibilidad hace tiempo del detalle de estas operatorias, entonces a la gente le informamos mejor, o sea sabe señora de esta manera usted nunca va a tener vivienda, entonces pásese al tramo con crédito y como tiene residencia recién, en cinco años va a tener un ahorro mayor y posibilidad que le den». 
Muchas veces son los mismos funcionarios municipales quienes, de manera voluntariosa, intentan resolver esta falta de información a los usuarios, acudiendo a otros territorios de sus municipios, e incluso al consulado peruano, con el fin de dictar charlas informativas que posibiliten el acceso a estos servicios públicos. Cuestiones relativas a la ficha de protección social, los requisitos para acceder a subsidios y la sensibilización respecto de la importancia del ahorro voluntario, entre otras, constituyen los elementos centrales de esta labor de difusión. La evaluación a este respecto es positiva desde el nivel municipal, donde se reconoce que los migrantes peruanos son más «disciplinados» que los usuarios chilenos respecto del cumplimiento de muchos requisitos, alcanzando las actuaciones municipales en las que el beneficiario es extranjero un 5\% en Santiago.

Desde la perspectiva del migrante la situación de bloqueo producida por las exigencias impuestas reduce las expectativas de que sea la asociatividad la que permita concretar la solución al problema de la vivienda: «Algunos estamos 15 años, 20 años, siempre alquilando y cada vez más elevados y la vivienda está mal en sistemas de servicio, sobre todo mucho se ha visto en el centro en Independencia, en La Paz, se han visto accidentes y solo los dueños le ven el lucro de arrendar una casa y aprovechando sobre todo de los migrantes o se dieron cuenta de mi situación sabía que yo estaba en un Comité, porque le dije, yo años en un Comité de Vivienda. Ahí fuimos para allá donde la mamá que mostró la hoja, para mostrar que de verdad yo pertenecía al Comité, porque yo estaba desde el 2009. Entonces la gente dijo, no si ella está en este comité'».

Por otro lado, se aprecia en los discursos una alta valoración de las redes constituidas en torno a los lugares de residencia, no sólo en cuanto vínculos familiares, sino también como facilitadores del acceso a los servicios públicos como colegios, salud y municipio. Queda claro que las imágenes construidas en torno a la discriminación no son «fantasmagorías»: «es que encuentran en Chile mucha facilidad para todo, tienen casa, salud y consultorios y es que las peruanas han tomado la mala costumbre, estas peruanas, de dejarse embarazar aquí y entonces sus hijos van a ser chilenos y entonces después la migración son hijos chilenos y no pueden ingresar a Perú».

Desde las estructuras asociativas de los migrantes también se denuncia, por parte de sus dirigentes, una cierta discriminación en el acceso a los servicios estatales. Un conjunto de obstáculos basados en la nacionalidad del demandante se interponen en el otorgamiento de los respectivos subsidios: «pero algunos funcionarios le dan prioridad mayor a lo que sea preferible chileno que sea un extranjero. Entonces habrá un punto de vista legal de unirnos todos los comités y trabajar con el SERVIU y direccionar hacia un punto de derecho que nos tengan en cuenta, nos tengan en cuenta que sea el subsidio 1 o 2 y que se haga el proceso de los trámites, porque tenemos sobre todo ese derecho de poder vivir en un hogar digno y a la misma vez ver nuestros hijos no vivir bajo de un 


\section{techo muy limitado, sufrimos y sobre todo nuestros hijos que están estudiando» (Dirigente comité de vivienda comuna de Recoleta).}

Más allá de la disposición y/o actitudes de algunos funcionarios, existen normativas que limitan el acceso a estos subsidios por parte de los migrantes. Nos referimos específicamente a los requisitos de residencia definitiva y permanencia en Chile por al menos cinco años, que han comenzado a exigirse para acceder a los subsidios. En este sentido, la precariedad e inestabilidad de los sectores de empleo en que se insertan mayoritariamente los migrantes obstaculizan seriamente la obtención de la residencia definitiva, incluso en casos en los que la permanencia en Chile supera el períodos estipulado de cinco años. Observamos entonces la configuración de una doble barrera que deben sortear los migrantes; por un lado, en el orden de las actitudes de los funcionarios chilenos con quienes deben tratar, y por otro, en los requisitos jurídico-administrativos que comienzan a exigírseles.

Según se aprecia, los agrupamientos de migrantes en determinados barrios de algunas comunas de Santiago, generados básicamente a través de redes de familiares y amigos establecidos previamente en el país, buscan consolidar los apoyos para la obtención de trabajo y posibilitar una «integración diferenciada». Es decir, como peruanos realizan una actividad laboral que les permite obtener una remuneración sin necesariamente desempeñarse en su campo de especialidad, pero buscan mantener sus costumbres y estilo de vida particular, en los modos de ocupación tanto de la ciudad, el barrio y el espacio vital de la manzana o el vecindario. La idea que prevalece es que el agrupamiento impide la desprotección y el desamparo en diversos planos, ya sea el laboral, de cuidado de los niños, de gestiones para acceder a la atención de salud, etc.

Estas dinámicas de ocupación de la ciudad, generadoras de barrios étnico-nacionales, provocan una separación entre los «unos» y los «otros», entre «nosotros» y «ellos», organizando o determinando modos de relación entre la población chilena y la población migrante, y condicionando muchas veces las formas de actuación de la institucionalidad pública en territorios específicos de la región Metropolitana. En este sentido, no sorprende que la entrevista realizada a un inspector municipal de la comuna de Independencia haya estado marcada por juicios xenófobos, comprensibles en cuanto consecuencia de la construcción de esta frontera simbólica que separa a migrantes y autóctonos en el discurso de estos últimos. Alusiones a una supuesta «suciedad intrínseca de los peruanos», o a que «habrían traído la tuberculosis a Chile», expresan la ambivalencia y carácter complejo de las representaciones sociales, pues hay un discurso político oficial de los funcionarios y otro más coloquial que circula entre iguales esto es, entre chilenos. Consultado sobre los criterios utilizados para definir los territorios y recorridos de las inspecciones, el funcionario hace hincapié en los barrios donde residen «hacinadamente» los pequeños emprendedores peruanos y comienzan a instalar sus comercios. El espacio local, marcado por la convivencia entre chilenos y extranjeros, comienza a ser objeto de estigmatización por parte de un discurso que le otorga una carga negativa a 
partir de la supuesta falta de urbanidad de sus habitantes, o de una igualmente supuesta carencia de civilidad.

El discurso de los migrantes se organiza bajo el supuesto de que la protección social o apoyo estatal dependerá en gran medida de su capacidad de articulación con redes familiares y de amistades, que a su vez son portadoras de los saberes y contactos que los proveerán de estrategias o soluciones, empujándolos a organizarse para obtener una vivienda. La formación de comités de vivienda es vista de forma clara como una respuesta a la discriminación percibida como proveniente del nivel gubernamental, en cuanto los requisitos de permanencia en el país para postular a beneficios han cambiado. Así también a nivel municipal, cuando se percibe que los funcionarios no entregan la información necesaria o «tramitan» a los solicitantes más de lo debido. En este sentido hay una discriminación tanto por el lugar de residencia y condición de hacinamiento como en el proceso mismo de postulación a la vivienda; ambas formas de discriminación son resistidas por los migrantes a través de las redes de apoyo y la asociatividad.

\section{Conclusiones}

Debemos partir por señalar la directa relación observada entre la situación jurídica de los migrantes peruanos y las representaciones sociales que construyen respecto de los servicios públicos. Su contacto con los servicios estudiados tiene como condición inicial la situación legal o ilegal en la que se encuentren, pues ésta determina las formas de representarse estos servicios, ya sea como una amenaza, como una potencial ayuda o como un servicio garantizado en cuanto derecho. Las apreciaciones más críticas respecto de estos servicios aparecen cuando los migrantes saben que no tienen la posibilidad de exigir nada ante el funcionario público, que se encuentran a su arbitrio y que, por tanto, pueden ser discriminados sin que exista la opción de quejarse. Es en el marco de esta experiencia que desarrollan estrategias diversas para resolver los problemas que les salen al camino, ya sea recurriendo a sus redes de apoyo familiares, amigos connacionales o construyendo lazos personales con chilenos capaces de resolver sus problemas específicos.

Estas representaciones tienden a variar cuando los migrantes tienen la certeza, jurídicamente respaldada, de que les corresponden determinados derechos conciencia de derechos, lo que puede deberse a que cuentan con visa o a que están trabajando, «con los papeles al día», con cotizaciones previsionales y de salud. En esta situación la comparación entre los servicios locales y los de su país es más «objetiva» o moderada, en tanto reconocen en los servicios chilenos ciertas bondades, y lo hacen como usuarios plenos y no excluidos. También puede evaluar las debilidades de los servicios y determinar cuándo se enfrentan a situaciones propias de un déficit endémico del Estado, por un lado, y cuándo ellas corresponden, más bien, a simple arbitrariedad y discriminación por su condición de peruanos, por otro. 
En la misma línea, reconocen la buena calidad de los servicios de salud hospitalarios, en particular la atención materno-infantil, incluido el parto, cuya cobertura es más amplia en Chile que en el Perú. En el ámbito de la educación municipal señalan que su nivel de cobertura es similar en ambos países, aunque consideran que la calidad de la educación pública chilena es peor. El programa de viviendas aparece como una opción aún bloqueada por escollos legales.

\section{Cuadro 4. Representaciones sociales: cuadro resumen.}

\begin{tabular}{|c|c|c|}
\hline \multicolumn{3}{|c|}{ REPRESENTACIONES SOCIALES: CUADRO RESUMEN } \\
\hline Servicio público & Dimensiones & Ejes \\
\hline \multirow[t]{2}{*}{ EDUCACIÓN } & Convivencia escolar & Derechos - Bullying \\
\hline & Inclusión social & Integración - Discriminación \\
\hline \multirow[t]{2}{*}{ SALUD } & Acceso & $\begin{array}{l}\text { Dificultades y facilidades - } \\
\text { Estrategias }\end{array}$ \\
\hline & Calidad & Respeto - Discriminación \\
\hline \multirow[t]{2}{*}{ VIVIENDA } & Mercado inmobiliario & $\begin{array}{l}\text { Discriminación - Estrategias de } \\
\text { asociatividad }\end{array}$ \\
\hline & Vivienda & $\begin{array}{l}\text { Amenaza de desprotección - redes } \\
\text { de apoyo }\end{array}$ \\
\hline
\end{tabular}

Desde otra perspectiva, hemos podido observar una conciencia respecto de la historia de conflictos entre ambos países, y de las dificultades que ella acarrea para su integración, conciencia que a su vez fortalece la identidad propia. Esto pareciera indicar que la integración de los migrantes peruanos no se producirá por asimilación, sino, más bien, a través de la vía del reconocimiento jurídico y cultural del aporte que realizan en un país que se pretende moderno. Las representaciones construidas en torno a los servicios públicos chilenos, con sus episodios de discriminación, arbitrariedad y exclusión, también han ayudado a generar dinámicas de integración al interior de la comunidad peruana de origen popular, con un doble movimiento: por una parte, acudir a los servicios sociales disponibles con el fin de resolver los problemas de sobrevida y bienestar básico, y por otra, acentuar las relaciones con sus connacionales con el objeto de fortalecerse colectivamente ante una sociedad percibida como hostil y abusiva cuando no se cuenta con los papeles en regla o se tiene un trabajo precario.

La idea de respeto por la persona, por sus costumbres, por su nación 
de origen, posee una alta valoración entre los migrantes peruanos, quienes deben sobreponerse no sólo a la discriminación generalizada que los chilenos manifiestan hacia los migrantes «no europeos», sino también al rechazo específico, cargado de simbolismos históricos, que los vincula con la guerra del siglo XIX. Más que un simple producto de la tendencia demográfica a instalarse en barrios antiguos y deteriorados, la inclinación hacia la agrupación en barrios expresa una forma de fortalecer la vida en común, un «espacio protegido» y de demostración de unidad cultural manifestada en la vida pública local. Así lo demuestran los asentamientos peruanos en comunas como Peñalolén, Renca y Cerro Navia, entre otras.

Las representaciones sociales de los peruanos migrantes respecto de los servicios públicos chilenos se aproximan a considerarlos como una «ventaja» que viene aparejada a la migración, pero ello no implica que esta ventaja se conciba como un «regalo» o «favor», sino más bien como un derecho que les corresponde. Las representaciones sociales se basan en experiencias pasadas directas e indirectas que operan como referentes para las prácticas presentes, por lo que es posible afirmar que las formas de relación con los servicios públicos del lugar de origen bastante desiguales según éste sea urbano o rural tienen un peso importante en las formas de relación y expectativas que los migrantes establecen luego con los servicios públicos chilenos. Como ya hemos afirmado, este análisis posee un común denominador, que es la condición legal en la que se encuentran los migrantes al momento de establecer contacto y relacionarse con estos servicios. De lo anterior se desprende que, de acuerdo a los discursos analizados, la población peruana residente en Santiago tiene una mayor conciencia de sus derechos y también un manejo de la normativa legal local que les permite adaptarse según su situación jurídica. De ahí que al entrar en contacto con los funcionarios públicos de los servicios locales aparezcan como «firmes»y respetuosos, exigiendo una atención como la que se brinda a cualquier persona, libre de abusos.

En este panorama, el Estado chileno aparece, en comparación con el peruano, como dotado de una estructura más ordenada, pero ello no es necesariamente una ventaja, en tanto exista discriminación en la atención, el trato hacia los hijos o en el ambiente laboral. En el imaginario migrante, en efecto, el Estado chileno posee una mayor capacidad de control social y de efectividad en la imposición de sus normas en diversos campos de su competencia y en relación con los migrantes. En este sentido, se le reconoce una mayor presencia, aunque no necesariamente un funcionamiento más eficiente. Se asume que hay una mejor organización de los servicios, pero también que éstos operan con grados de discriminación: el Estado se transforma en un aparato eficaz de discriminación. A la vez, los migrantes son conocedores de las fisuras existentes en los distintos puntos de control instalados en la burocracia; en ocasiones las usan a su favor, como cuando acceden a prestaciones de salud a través de relaciones personales, o cuando la ley no se aplica para proteger a quienes trabajan en condiciones abusivas, con salarios injustos o sin descuentos previsionales. 
La Ley de Extranjería se ha visto sobrepasada, no sólo por el mayor flujo de migrantes peruanos, sino también porque éstos han logrado hacerla poco aplicable, en tanto han desarrollado estrategias de inserción social que están contribuyendo a un cambio cultural en diversas esferas de la sociedad (economía, gastronomía, servicios, etc.). Lo anterior tensa la relación con un Estado que aún piensa en la «inmigración selectiva» de europeos, mientras los mercados presionan por la aceptación de esta población con ciertas competencias laborales ventajosas en el contexto del actual ciclo económico ${ }^{2}$. El marco jurídico vigente, más que ayudar al proceso de integración sociocultural, está generando formas de exclusión y discriminación que resultan contraproducentes respecto de la propia economía del país, en tanto permite la existencia de una fuerza laboral indocumentada, legal y socialmente desprotegida, con una alta inseguridad laboral, que no cotiza en el sistema de salud y previsión social. En la lógica de construir una nueva política migratoria en Chile iniciativa discutida al menos desde el mandato de Michelle Bachelet (2006-2010) resulta importante comprender que las representaciones sociales acerca de los servicios públicos descritas en el presente artículo tienen una validez restringida a la experiencia migratoria santiaguina. El carácter más bien permanente del asentamiento peruano en la capital contrasta con otros patrones o perfiles migratorios observables en las regiones extremas y fronterizas. Las dinámicas de circuito migratorio, transnacionalidad o translocalidad determinan otras formas de relación con los servicios públicos, y a nuestro juicio demandan otro tipo de tratamiento en el marco de una nueva política migratoria en Chile. 


\section{Notas}

${ }^{1}$ FONASA tiene segmentados los montos de las cotizaciones según niveles de ingreso. Nivel A para indigentes, nivel B para ingresos menores al sueldo mínimo, y niveles C y D para ingresos superiores al sueldo mínimo, y deben realizar un copago según la prestación de salud.

${ }^{2}$ El crecimiento del PIB entre los años 2000-2010 fue de un 3,8\% promedio anual. Bibliografía. 


\section{Bibliografía}

Anduiza, E.; Crespo, I. y Méndez, M. (1999), Metodología de la Ciencia Política, Madrid, CIS.

Arango, Joaquín (2003), “La explicación teórica de las migraciones: Luz y sombra”. En Migración y desarrollo, $\mathrm{N}^{\mathrm{0}} 1$. Disponible en: www.migracionydesarrollo.org

Araujo, Kathya; Legua, María Claudia y Ossandón, Loreto (2000), Migrantes andinas en Chile. El caso de la migración peruana. Fundación Instituto de la Mujer.

Garcés, Alejandro (2011a), “De enclave a centralidad. Espacio urbano, comercio y migración peruana en Santiago de Chile”. Gazeta de Antropología 27 (2). Disponible en: http://www.ugr.es/ pwlac/ G27_38Alejandro_Garces.html

Ídem (2011b), “Comercio inmigrante y economías étnicas: síntesis y críticas de los debates vigentes”. Polis, Revista Académica Universidad Bolivariana 29. http://revistapolis.cl/29/art04.htm

Glick Schiller, Nina; Basch, Linda y Blanc-Szanton, Cristina (1992), "Towards a definition of transnationalism.Introductory remarks and research questiones”. En: N. Glick Schiller, L. Basch y C. Blanc-Szanton Towards a transnational perspective of migration. Race, class, ethnicity and nationalism reconsidered. ix-xiv, New York

Hall, Stuart (1997), “El trabajo de la representación”, en Stuart Hall (ed.), Representation: Cultural Representations and Signifying Practices. Cap. 1, pp. 13-74. Traducido por Elías Sevilla Casas, Sage Publications, London.

Hernández, Roberto; Fernández-Collado, Carlos y Baptista, Pilar (2006), Metodología de la Investigación, Mc Graw Hill, México.

Ibáñez, Tomás (1988), Ideologías de la Vida Cotidiana, Sendai, Barcelona.

Jodelet, Denise (1989), "Représentations sociales: un domaine en expansion”, en Les représentations sociales. PUF, pp. 31-61, París.

Kearney, Michael (1986), "From the Invisible Hand to Visible Feet: Anthropological Studies of Migration and Development”. Annual Review of Anthropology 15: 331-361.

Luque, José (2007), “Asociaciones políticas de inmigrantes peruanos y la «Lima Chica» en Santiago de Chile”. Migraciones Internacionales 4 (Num. 2): 121-150. 
Martínez Pizarro, Jorge (2003a), Breve examen de la inmigración en Chile según los datos generales del Censo de 2002. OIM-Chile, Santiago.

Ídem (2003b), “El encanto de los datos. Sociodemografía de la inmigración en Chile según el censo de 2002”. CEPAL Serie Población y Desarrollo 49: 1-60, Santiago.

Ídem (2005), Magnitud y Dinámica de la Inmigración en Chile, según el Censo de 2002. Papeles de Población, $\mathrm{N}^{\circ} 044$, Universidad Autónoma de México.

Moscovici, Serge (1961), "La representación social: un concepto perdido”, en El Psicoanálisis, su imagen y su público, Ed. Huemul, 1979, 2da edición. Cap. I, pp. 27-44, Buenos Aires.

Ruiz Olabuénaga, José (2003), Metodología de Investigación Educativa, Editorial Universidad de Deusto, Bilbao.

Solé, Carlota; Parella, Sonia; Alarcón, Amado et al. (2000), “El impacto de la inmigración en la sociedad receptora”. Revista Española de Investigaciones Sociológicas 90: 131-157, Madrid.

Stefoni, Carolina (2002), Inmigración peruana en Chile: una oportunidad a la integración. Editorial Universitaria, Santiago.

Recibido: 25.01.2013

Aceptado: 25.07.2013 